In 1848 Bernard began the series of investigations on the nature of the processes to which substances absorbed from the gastro-intestinal tract of animals were subjected during their passage through the body. The results of these investigations were summarised in Bernard's thesis for the Doctorate of Science, which was published in 1853 under the title Nouvelle fonction du foie. It described his perhaps most famous discovery: the glycogenic function of the liver. From 1853 onwards many publications by Bernard document his scientific development.

Bernard's Introduction à l'étude de la médecine expérimentale, published in 1867 as the result of a period of illness which kept him from his lecture room and research bench, gives what can be perhaps an idealised treatment of his subject and of the views that he had assumed by the time he had become an internationally distinguished investigator. Professor Holmes quotes from Bernard's writings later in life the statement that "For more than two years, at the beginning of my career, I wasted my time pursuing theories and chimeras. It is a remark-

able fact, that one imagines that the truth is in himself, and I insisted on repeating experiments which insisted on responding to me always in the same way, contrary to my views. It was not until after a long deception that $I$ ended by reflecting and thinking that ... my will could not change the laws of nature".

As Professor Holmes states, Bernard's strength was tied to some serious limitations, and his avenue towards greatness was at first a narrow one. There was no guarantee that his will, his insights and his technical skill would lead him to the heights. During the 1840 s he was not somebody consciously advancing towards his position of the $1850 \mathrm{~s}$ and $1860 \mathrm{~s}$, but one whose fate was uncertain. "The prospect of returning to Villefranche as a village doctor was as real for Claude Bernard as the prospect of ascent to the Académie des Sciènces, the Académie Française and the adulation of his peers".

All who are interested in the way scientists develop will find fascinating material in this study of Claude Bernard during his early years.

F. G. Young

\title{
Scientific knowledge and sociological theory
}

Scientific Knowledge and Sociological Theory. By Barry Barnes. Pp.x +192. (Routledge and Kegan Paul: London, December 1974.) $£ 3.95$ cloth: $£ 1.95$ paper.

IN spite of its Germanic title and subject matter, Scientific Knowledge and Sociological Theory is a brief, elegantly written, and even occasionally witty discussion of the social and cultural factors affecting the development of scientific knowledge. It represents an ambitious attempt to apply the perspectives of Mannheim's sociology of knowledge to science.

Barnes rejects conventional distinctions between false beliefs, which require causal explanation, and "naturally reasonable inductions", which do not. He also rejects the definition of science as rational, rather than true, knowledge, on the grounds that there are no adequate criteria for comparing the rationality of different statements: simplicity is ambiguous, and conventional; falsifiability is impossible to establish, and rarely used in practice; and ad hocery is merely a derogatory term for secondary elaboration or rational modification. For Barnes, all knowledge is necessarily theoretical, for there is no direct language of observation, and theoretical acceptability is culturally conditioned. Therefore, all knowledge is equally susceptible to sociological explanation.

Normality, defined by the actors themselves, is substituted for truth or ration- ality as the yardstick for comparing different beliefs; abnormality, rather than falsehood or irrationality, requires causal explanation. "Where actors or groups hold idiosyncratic beliefs as judged against some background of normality, some special cause or condition must be identified which distinguishes that actor or group from that background" (p. 42). Barnes, therefore, focuses upon the maintenance of normality and the development of innovation within scientific sub-disciplines. Normal beliefs are learned through socialisation into the distinctive metaphors and procedures of scientific subcultures, by following exemplary procedures, and by acquiring practical experience. Innovation occurs through differentiation, transfer from one subdiscipline to another, or simply from creativity based upon "a universal human propensity to create and extend metaphors" (p. 87). Such innovations occur partly through the intellectual evolution of conventional paradigms within science itself, and partly through the need to develop new beliefs to fulfil purposes external to science. Thus, the Scientific Revolution resulted partly from the re-emergence of Platonism, and partly from the disintegration of feudalism as a political and social system: "in the general context of post-feudal Europe, teleology had to decline" (p. 117).

The substitution of normality for truth or rationality represents only a formal, if fashionably relativist, advance upon previous usage. What are the criteria for 'normal'? Is normality to be interpreted in a statistical or cultural sense? Are actors always conscious of the normality or otherwise of their actions? Moreover, rationality can, for 'practical purposes', provide a basis for comparing beliefs in terms of given means-ends relationships. Problems arise with the concept of rationality only when it is impossible to specify ends, that is, at the most general level. But, as Barnes points out, science consists of a number of differentiated subcultures, each with distinctive procedures and ends. The problems of rationality are, therefore, less than Barnes initially suggests.

In general, the sociology of knowledge provides an unsatisfactory basis for explaining scientific knowledge, for the connections between specific beliefs and the social structure remain tantalisingly vague. Barnes argues sensibly that "the sociologist should consider beliefs in terms of their functions in practical activity" (p. 39) and brings out clearly the general factors that might connect science with that activity. But the illustrations of those connections are disappointingly brief and often unconvincing: uniformitarianism as the credo of an emerging industrial order in early nineteenth century Britain and eugenics in Britain before 1914 as a response of the declining ruling class are presented as self evidently plausible examples. At the very least, some attempt at a comparative analysis of alternative reactions is required. Moreover, Barnes shows considerable sympathy for materialist explanations of scientific development (for example, pp. 149-50), but does not discuss the connection between the material bases for the production of science and the content of scientific beliefs in any detail.

The approach to sociology adopted by Barnes is explicitly 'phenomenological', although his use of the approach is valuably flexible. This involves "an appreciation of actors' normal practice as it is, and of its inadequacies as they themselves define them" (p. 43). In practice, however, the author disregards the self imposed limitations this perspective volves, and his analysis of innovation acknowledges the problematic validity of actors' own explanations. This tension, if not inconsistency, stems from the author's recognition that actors' accounts cannot in themselves provide a basis for sociological generalisation and explanation.

In spite of these unresolved problems Scientific Knowledge and Sociological Theory represents a valuable and interesting contribution to sociology. At the very least it provides sociologists with an unusual gritty insight into the reality of science. But I doubt whether the book will persuade scientists that sociology has much to offer them in their own 'practical concerns'. Roderick Martin 